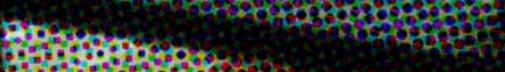

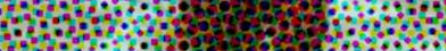

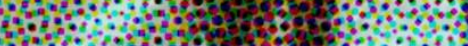

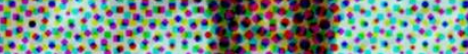
and

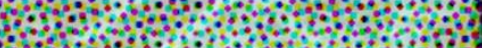

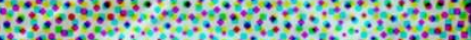

\section{RESENHA DO FILME SEM PENA}

\section{Wendell Marcel Alves Costa}

Graduando em Ciências Sociais. Bolsista PIBIC/CNPq na área de Cinema.

E-mail: marcell.wendell@hotmail.com

\section{REFERÊNCIA DA OBRA EM ANÁLISE}

SEM PENA. Direção de Eugenio Puppo. Brasil: Heco Produções, Espaço Filmes e Prefeitura de São Paulo, 2014. Documentário, 86min, son, col. 


\section{PERSPECTIVA TEÓRICA DA OBRA}

"Coloca um cavalo aqui dentro e vê quanto tempo ele dura".

O filme Sem Pena (PUPPO, 2014) corrobora algumas questões que são vigentes no sistema penitenciário brasileiro. Com uma visão crítica dos fatos, o diretor preconiza no enredo do documentário, elementos sobre as relações envolvendo justiça, pena, crime, cenário do crime, evidência, culpa, sujeição e, no último momento, evasão da dignidade humana frente ao desperdício dos sujeitos em cárcere.

Esses temas são debatidos através de diferentes perspectivas, desde juízes, promotores, assistentes sociais e antropólogos a criminosos e acusados. Essa linha de reflexão sob visões posicionadas em status sociais e empoderamento político diferenciadas, cria um cenário dialético que conduz de forma profunda e muitas vezes sombria aos interesses que regem a instituição criminal do país, em todos os seus desafios e perspectivas.

Cada vez mais os atributos relacionados aos direitos humanos e sua representação nos meios de comunicação ganham ênfase quando o assunto é o comprometimento da Justiça em face do crime cometido. Logo, surge um sentimento de inju stiça, de impunidade, gerando um mal-estar coletivo, mirando justamente nos agentes protetores dos direitos dos indivíduos em situação criminal. A interpretação desajustada e ideologizante da mídia, concebe um imaginário social sobre as tecnologias sociais que não conseguem suprir os desafios que a violência traz, fomentando um estado psíquico de medo, preocupação e de mantimento da proteção contra os "seres do mal".

De certo, uma série de equívocos é dirigida aos agentes sociais (assistentes sociais, delegados, promotores, juízes, psicólogos, advogados) como também a conceitos atribuídos aos campos da Justiça. Esse painel geral, que tem como foco a Justiça, tem uma implicação severa na construção dos discursos da população: quando um crime é cometido, precisa ser encontrado o criminoso, e aqui rege a lei popular e histórica "olho por olho, dente por dente". Os casos em que essa ação encontrou resultados reais são inúmeros.

Contudo, Sem Pena trabalha exatamente com as formas em que se estruturam socialmente e politicamente, observadas anteriormente, percebendo na lógica do aprisionamento uma saída pouco hábil e inteligente para alcançar resultados 
significativos. Não é, entretanto, uma obra que facilita o entendimento da lógica prisional; torna-a superlativa.

\section{BREVE SÍNTESE DA OBRA}

"Pior do que ficar preso foram os anos que demorou para ter o processo".

O documentário Sem Pena conduz a uma narrativa que se distancia da posição de entrevistados de frente à câmera. Não são perguntas e respostas. Nem tampouco closeup nos rostos dos acusados, dos criminosos, promotores e juízes. Portanto, não existe no filme uma representação social completa dos sujeitos que narram os seus acontecimentos; dessa maneira, os espectadores estão necessariamente a mercê dos discursos proferidos por eles. Estamos sem provas. A cena do crime deverá ser produzida tão somente pelas informações transmitidas pelas vozes em off recorrentes durante a exibição.

Essa opção requer primordialmente uma posição de ouvinte, literalmente, do espectador. Ele precisa estar atento às palavras dos entrevistados que, ironicamente, não possuem cabeças. Esse fato leva-nos a crer que a adoção desse artifício estético é uma crítica direta ao meio televisivo e aos seus programas de horror que, presunçosamente, julgam moralmente e sentenciam diariamente homens e mulheres de terem cometido crimes. Esses programas de televisão vão contra aos direitos humanos, mostrando abertamente aos telespectadores os rostos assustados e os olhos baixos de crianças e jovens que eventualmente cometeram crimes.

Nesse sentido, é por meio da narração dos entrevistados e, principalmente, na condução de uma trilha sonora muito bem elaborada por John Cage que o filme produz um espaço de debate acerca de pessoas envolvidas em situações de crime, e que são involuntariamente postas, sem pena, contra o Estado.

\section{PRINCIPAIS TESES DESENVOLVIDAS NA OBRA E REFLEXÕES CRÍTICAS}

\footnotetext{
"Se nós não compreendermos o abismo social onde nós estamos todos afundados, nós não vamos jamais resgatar uma coisa que se chama dignidade".
} 
A linguagem cinematográfica está muito presente neste documentário de Eugenio Puppo. O uso de certos elementos constitui a obra como um dispositivo de reflexão sobre temas relacionados à criminalidade. Como montador do filme, Puppo realiza cortes secos na transição entre imagens escuras e claras, mesclando os ambientes por onde circula com as áureas morais que lhe são atribuídas socialmente. Esse fato pode ser identificado nos enquadramentos do prédio da Faculdade de Direito e dos presídios que são visitados pelo diretor e seu diretor de fotografia, Jorge Maia.

Além da edição tecnicamente irretocável, a trilha sonora também realiza um papel de destaque na narrativa. Os sons de grades dos presídios batendo e ruídos metálicos confundem-se com a composição da trilha sonora do filme, compondo uma sonoridade específica e marcante na obra. Esses elementos, tanto sonoros quanto da fotografia, constroem uma narração que se desenha na estruturação da tese central do longametragem: a implicação de Justiça que não atinge a todos de forma igualitária.

Em certo momento do filme, um dos entrevistados comenta que uma pessoa que é pega com uma quantia ínfima de maconha é obrigada a cumprir uma pena ao lado de criminosos mais perigosos, verdadeiros chefes do tráfico de drogas. Esse painel demonstra a direção que a execução penal no Brasil tomara, claramente um sentido rarefeito no cumprimento de medidas que lhe seja substancialmente atraente aos olhos do mercado de consumo de resultados. Esse discurso é igualmente compartilhado por promotores e estudiosos da criminalidade, pois a Polícia Militar hoje é condecorada mais pela sua função de prender e matar, atribuindo aos altos números de cárcere os falsos resultados de sua falha operacionalização.

Essa lógica torna-se mais assustadora com as imagens iniciais do filme, quando imensas colunas e corredores sem fim guardam caixas desgastadas cheias de papeis de processos aguardando julgamento. É um grande contraponto aqui desenvolvido pelo diretor em apresentar essas imagens, e logo em seguida, em um claro corte ideológico, dar a palavra ao primeiro entrevistado.

De forma fantasmagórica, as primeiras palavras de um dos entrevistados são como a abordagem da própria população, os civis, encontra uma terrível reação em cadeia de acasos que ilustram um verdadeiro filme de terror. Cenograficamente falando, essa sensação encontra uma noção, ainda que virtual repercutida na imaginação dos espectadores, através dos desenhos horripilantes produzidos pelo nosso emissor. Esse momento do filme é decisivo em anunciar os capítulos que se seguirão, e também de prenunciar uma certeza que lhe é cabível: no combate entre o mais forte e o mais fraco, o 
forte sempre vence. Em outras palavras, na certeza de que as evidências são coerentes, o acusado não consegue se defender frente ao Estado.

Mormente, como se defender frente ao Estado? No Brasil, diz-se que se vive em um Estado Democrático de Direito. No entanto, esse mesmo Estado está carregado de heranças oriundas de um sistema de execução penal retrógado. A burocracia é o verdadeiro vilão da história, e nesse caso, cabe ao jeitinho brasileiro destituir da Justiça a penalização dos atos cometidos pelos sujeitos. Quando não, são os erros nas execuções penais, como é o caso de uma das entrevistadas que foi presa por possuir um número tal de cannabis, que levam os sujeitos a acreditar na Justiça falha.

Como resultado a essa burocracia institucionalizada, a pena tem como função a saída para fugir de questões complexas da sociedade, como a segurança, a política local e a defesa por uma educação ampliada. A penalização e, conseguintemente, a vigilância torna a sociedade um espetáculo teatral, onde os desafios e as incertezas do sistema só são expostas quando uma crise criminal se instala na realidade próxima da população, como nos bairros ou nos centros de convivência.

Por consequência, as vítimas do Estado burocrático e das medidas paliativas que sobrecarregam setores administrativos também falhos do governo, como a educação e a segurança, são os negros, pobres e aqueles que estão em moradia em situação de rua. Como já demonstra a história, o negro não teve ainda uma integração à sociedade de classes no Brasil, e as consequências desse processo inacabado se refletem no alto índice de marginalização, de abandono da escolaridade e na admissão de uma vida amoral dos negros. Não por acaso, as penitenciárias do país têm, em sua maioria, uma população negra, pobre e masculina; e a sua família, também negra e pobre, termina por se sujeitar a várias humilhações deixadas pela herança imoral desses homens e mulheres encarcerados.

A respeito disso,

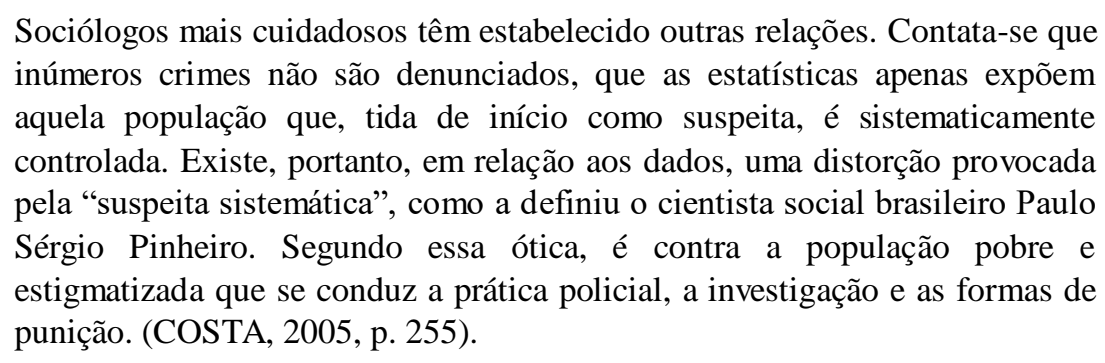

Sabe-se que ao fim do regime escravocrata no Brasil, o negro escravizado, vendo-se liberto, se deparou com um grande desafio, o de ser senhor de si mesmo, pois 
nem seu antigo senhor, nem o Estado ou a Igreja se disponibilizaram para dar-lhes amparo e nem tampouco de prepará-los para o novo regime. Desse modo, a Abolição teve caráter de um desapossamento cruel para o negro que agora se via sem ter para onde ir. Os negros e mulatos, na transição da escravidão para a liberdade, não contavam com nenhum recurso que lhes conferissem autonomia econômica, social ou política, ficando assim totalmente à mercê de uma sociedade que os repulsavam, tratando-os indignamente em sua condição de libertos, o que provocava, entre eles, um protesto mudo, devido à sua desilusão social (FERNANDES, 2008).

Analogamente, percebem-se dois fatos que são comuns entre si: a socialização da população encarcerada. Assim como no século XIX, com a Abolição da escravatura no Brasil, os homens e mulheres que se veem libertados depois de dois, cinco, dez ou vinte anos, não conseguem se inserir a sociedade. E mais: não reconhecem os códigos e processos sociais vigentes no mundo novo que agora são deles, depois de tantos anos prisioneiros do sistema.

Neste tópico, o filme destaca bem os desafios trazidos pela liberdade. O grau de reincidência dos internos quando cumprem a sua pena e voltam à convivência social é altíssima. Isso se explica porque, estabelecendo a prisão como uma instituição total (GOFFMAN, 2013), o sujeito produz e converge em comportamentos, normas e códigos sociais aprazíveis ao meio criminoso dos seus pares. Destarte, segundo um dos entrevistados, a prisão é realmente "uma escola do crime", por que não existe neste âmbito nenhuma possibilidade de direcionar o pensamento para atividades lúdicas ou de construção de conhecimento.

Em resposta a isso, e levando em consideração o estigma sofrido pelos vizinhos e até mesmo pela sua família, o ex-interno volta a cometer crimes. A sua identidade virtual é mais forte que a sua identidade real (GOFFMAN, 1988). Essa é, em parte, uma das possibilidades apresentadas pelo filme de Puppo.

Nesse meio tempo, transparece no corrimento do filme a seguinte questão: afinal, qual o sentido das leis? Que resultados a aplicação das leis, sejam elas rigorosas ou leves em número de anos de encarceramento, podem trazer a sociedade? Que princípios morais são distribuídos na caracterização das leis?

Para compreender isto, embebedamos de Hobbes, na definição do que se diz por lei, sendo esta constituída: 
Pelas regras que o Estado lhe impõe, oralmente ou por escrito, ou por qualquer outro sinal suficiente de sua vontade, empregando tais regras para diferenciar o que é certo do que é errado, isto é, para identificar o que é contrário ou não é contrário à regra.

$[\ldots]$

As leis são as regras do justo e do injusto, não havendo nada que seja reputado injusto sem ser contrário a alguma lei. Ninguém pode fazer lei, a não ser o Estado, pois estamos sujeitos unicamente ao Estado; e as ordens devem ser expressas por sinais suficientes, pois, de outro modo, ninguém saberia como obedecer a elas. Portanto, tudo o que se possa ser deduzido dessa definição como conseqüência necessária deve ser reconhecido como verdadeiro. (HOBBES, 2002, p.212-213).

Todavia, a legalização da punição trazida pelas leis, não resolveram e não resolveram o problema da criminalidade. A criminalidade tem mais relação com a péssima distribuição de renda do governo e a sua herança política corrupta (CAPELATO, 1998), e com a urbanização massiva das grandes cidades litorâneas. A paisagem dessas metrópoles é representada em produções cinematográficas que destacam comumente os guetos, as favelas, a violência inerente a esses espaços, ao processo de "favelização" dos sujeitos dos morros em uma luta de classe tão antiga quanto à própria urbanização.

Por isso, incitar a punição de pessoas em situação de delito é um erro que confronta as pesquisas desenvolvidas nos campos da Sociologia e do Direito Penal. A filosofia também nos ajuda a entender melhor o fenômeno da punição em seus contextos históricos e culturais.

Na concepção de Foucault (2012), a arte de punir tem maior relação com a imagem e o efeito que essa ação trará para os indivíduos que são espectadores do ato, e no adestramento do sujeito penalizado. Para ele:

\footnotetext{
Encontrar para um crime o castigo que convém é encontrar a desvantagem cuja idéia seja tal que torne definitivamente sem atração a idéia de um delito. É uma arte das energias que se combatem, arte das imagens que se associam, fabricação de ligações estáveis que desafiem o tempo. Importa constituir pares de representação de valores opostos, instaurar diferenças quantitativas entre as forças em questão, estabelecer um jogo de sinais-obstáculos que possam submeter o movimento das forças a uma relação de poder. (FOUCAULT, 2012, p. 100).
}

É certo que a punição traz resultados graves ao interno. Não apenas o seu comportamento é transfigurado pela privação de liberdade, bem como a sua visão das coisas e das pessoas. O resultado não poderia ser o pior, a respeito do encarceramento: pessoas saídas de um ambiente mórbido, atroz e preparadas, mais do que nunca, diante das vicissitudes da realidade e das dificuldades financeiras, para o crime. 
Como o gênero documentário tem em seu alicerce conceitual um comprometimento mais forte com a vida, o filme transporta o espectador para uma realidade próxima a ele. O cinema-documentário constrói uma leitura sobre o fenômeno, adquiri um status de realidade cabível à compreensão do espectador e torna-se pura concretização do real. Essa concepção precisa ser afastada da leitura material de um produto audiovisual, pois este é uma concepção humana, e como tal, é subjetiva e artesanal sobre os processos culturais.

Alguns documentários se comprometeram a identificar o fenômeno do sistema judiciário brasileiro, por olhares artísticos, conceituais e políticos distintos. O longametragem Justiça (Maria Augusta Ramos, 2004) e os curtas-metragens impactantes de Aly Muritiba retratam bem o cenário audiovisual brasileiro que se dedica, de forma contundente, a problemática que vem ganhando destaque nacional e internacional: o Brasil é o terceiro país com a maior população carcerária do mundo, e está em contínuo crescimento.

Sem Pena é mais um título importante da cinematografia brasileira. Ao lado dos títulos acima citados, Sem Pena edifica uma posição sistemática, provocativa e contestadora sobre a real situação do sistema penitenciário do país.

\section{REFERÊNCIAS}

CAPELATO, Maria Helena Rolim. Estado Novo. Novas Histórias. In: Historiografia em perspectiva. FREITAS, Marcos Cezar (org.). São Paulo: Contexto, 1998.

COSTA, Maria Cristina Castilho. Sociologia: introdução à ciência da sociedade. São Paulo: Moderna, 2005.

FERNANDES, Florestan. A integração do negro na sociedade de classes: (o legado da "raça branca"). $5^{\circ}$ ed. São Paulo: Globo, 2008.

FOUCAULT, Michel. Vigiar e punir: nascimento da prisão. Rio de Janeiro: Vozes, 2012.

GOFFMAN, Erving. Estigma: notas sobre a manipulação deteriorada. Rio de Janeiro: LTC, 1988.

. Manicômios, prisões e conventos. São Paulo: Perspectiva, 2013. 
HOBBES, Thomas. Leviatã, ou Matéria, forma e poder de um Estado eclesiástico e civil. São Paulo: Martin Claret, 2012. 